\title{
Effect of Dealloying Condition on the Formation of Nanoporous Structure in Melt-Spun $\mathrm{Al}_{60} \mathrm{Ge}_{30} \mathrm{Mn}_{10}$ Alloy
}

\author{
Kang Cheol Kim, Won Tae Kim, Do Hyang Kim* \\ Center for Non-Crystalline Materials, Department of Materials Science and Engineering, Yonsei University, Seoul 03722, Korea \\ ${ }^{1}$ Department of Optical Engineering, Cheongju University, Cheongju 28503, Korea
}

*Correspondence to:

$\mathrm{Kim} \mathrm{DH}$,

Tel: +82-2-2123-4255

Fax: $+82-2-312-8281$

E-mail: dohkim@yonsei.ac.kr

Received September 22, 2016

Revised September 23, 2016

Accepted September 24, 2016
Effect of dealloying condition on the formation of nanoporous structure in melt-spun $\mathrm{Al}_{60} \mathrm{Ge}_{30} \mathrm{Mn}_{10}$ alloy has been investigated in the present study. In as-melt-spun $\mathrm{Al}_{60} \mathrm{Ge}_{30} \mathrm{Mn}_{10}$ alloy spinodal decomposition occurs in the undercooled liquid during cooling, leading to amorphous phase separation. By immersing the as-melt-spun $\mathrm{Al}_{60} \mathrm{Ge}_{30} \mathrm{Mn}_{10}$ alloy in $5 \mathrm{wt} \%$ $\mathrm{HCl}$ solution, Al-rich amorphous region is leached out, resulting in an interconnected nano-porous $\mathrm{GeO}_{\mathrm{x}}$ with an amorphous structure. The dealloying temperature strongly affects the whole dealloying process. At higher dealloying temperature, dissolution kinetics and surface diffusion/agglomeration rate become higher, resulting in the accelerated dealloying kinetics, i.e., larger dealloying depth and coarser pore-ligament structure.

Key Words: Amorphous alloy, Dealloying, Nanoporous structure

\section{INTRODUCTION}

Chemical or electrochemical dealloying method refers to a selective dissolution of less noble elements of the alloy, and is considered as one of the important corrosion process. By using such dealloying method, it is possible to fabricate nanoporous metals or oxides aiming to be used as catalysis, actuators, energy storage and biosensors (Chen et al., 2012; Qiu et al., 2015; Zhang et al., 2016). So far, it is known that various nanoporous noble metals such as $\mathrm{Au}, \mathrm{Pt}, \mathrm{Pd}$, and $\mathrm{Ag}$ can be fabricated by using dealloying method (Zhang et al., 2009), although high cost of them causes a problem in commercial applications. Recently, nanoporous metal such as $\mathrm{Cu}$ receives an attention due to their attractive properties and cost effectiveness (Wang et al., 2015).

It has been pointed out that to form an uniform nanoporous structure by using dealloying method, the precursor alloy is required to be a single phase. Until now, only several crystalline alloy systems have been found to be useful in fabricating uniform nanoporous structures through onestep dealloying process. In comparison with crystalline alloys, metallic glassy alloys consist of a single phase with a homogeneous composition and structure. The freedom for changing the constituent element and in changing the alloy composition makes metallic glassy alloys to be interesting systems for fabricating nanoporous structures which cannot be obtained from crystalline alloys.

Recently, it has been shown that amorphous $\mathrm{GeO}_{x}$ powder has a potential to be utilized as a new anode material for Naion batteries (Kajita \& Itoh, 2016). When the amorphous $\mathrm{GeO}_{\mathrm{x}}$ powders are used as the active material, they show high reversible capacity, high current discharge, and good cyclic charge-discharge performance. Such unique properties can arise from the amorphous structure of $\mathrm{GeO}_{x}$, which allows effective electrochemical $\mathrm{Na}$ insertion-extraction. Recently, it has been shown that amorphous $\mathrm{GeO}_{\mathrm{x}}$ nanoporous structure can be obtained by one-step dealloying of $\mathrm{Al}_{60} \mathrm{Ge}_{30} \mathrm{Mn}_{10}$ amorphous alloy (Kim et al., 2015). Such nanoporous $\mathrm{GeO}_{\mathrm{x}}$ is considered to be a good candidate for anode material for $\mathrm{Na}$ ion batteries, as mentioned above. Although the formation of uniform nanoporous $\mathrm{GeO}_{\mathrm{x}}$ has been reported in the previous study, the effect of dealloying condition has not been shown

(a) This is an open-access article distributed under the terms of the Creative Commons Attribution Non-Commercial License (http://creativecommons.org/licenses/by-nc/4.0) which permits unrestricted noncommercial use, distribution, and reproduction in any medium, provided the original work is properly cited.

Copyrights @ 2016 by Korean Society of Microscopy 
yet. Therefore, the aim of the present study is to show the effect of dealloying condition when fabricating amorphous $\mathrm{GeO}_{\mathrm{x}}$ nanoporous structure.

\section{MATERIALS AND METHODS}

An alloy ingot having a nominal composition of $\mathrm{Al}_{60} \mathrm{Ge}_{30} \mathrm{Mn}_{10}$ was prepared by arc melting the high purity elements (above 99.9\% purity) in a water-cooled copper crucible under an argon atmosphere. The alloy ingot was re-melted by highfrequency induction and then rapidly solidified into a ribbontype sample by ejecting the melt onto the surface of a $\mathrm{Cu}$ wheel rotating with a speed of $30 \mathrm{~m} / \mathrm{s}$.

Microstructural characterization was conducted using a transmission electron microscope (TEM, JEOL 2100F; JEOL, Japan) linked with an energy dispersive spectrometer (EDS; Oxford Instruments INCA, UK). The samples for TEM analysis were prepared using an Ar ion milling machine (PIPS 691; Gatan, USA) at $2.5 \mathrm{keV} / 6 \mathrm{~mA}$ under liquid nitrogen cooling.
De-alloying of the melt-spun ribbon was carried out in 5 wt $\%$ hydrochloric acid $(\mathrm{HCl})$ aqueous solution at $30^{\circ} \mathrm{C}, 40^{\circ} \mathrm{C}$, and $60^{\circ} \mathrm{C}$ for 100 hours. For TEM analysis, cross-sections of de-alloyed samples were prepared using a focused ion beam/ scanning electron microscope (FIB/SEM, Helios Nano Lab 600; FEI, USA).

\section{RESULTS AND DISCUSSION}

Fig. 1A and B show a typical bright field (BF) TEM micrograph and a high-resolution (HR) TEM image obtained from the as-melt-spun $\mathrm{Al}_{60} \mathrm{Ge}_{30} \mathrm{Mn}_{10}$ ribbon sample. The $\mathrm{BF}$ and HR TEM images show no appreciable contrast variation which is typical for monolithic amorphous alloy. However, the selected area diffraction pattern (SADP) shown in Fig. $1 \mathrm{C}$ clearly show double halo rings with high intensity instead of single halo ring which is observed in the conventional amorphous alloy. The observation of two halo rings indicate that the amorphous alloy consists two different amorphous phase with different compositions (Kim et al., 2015). Since it
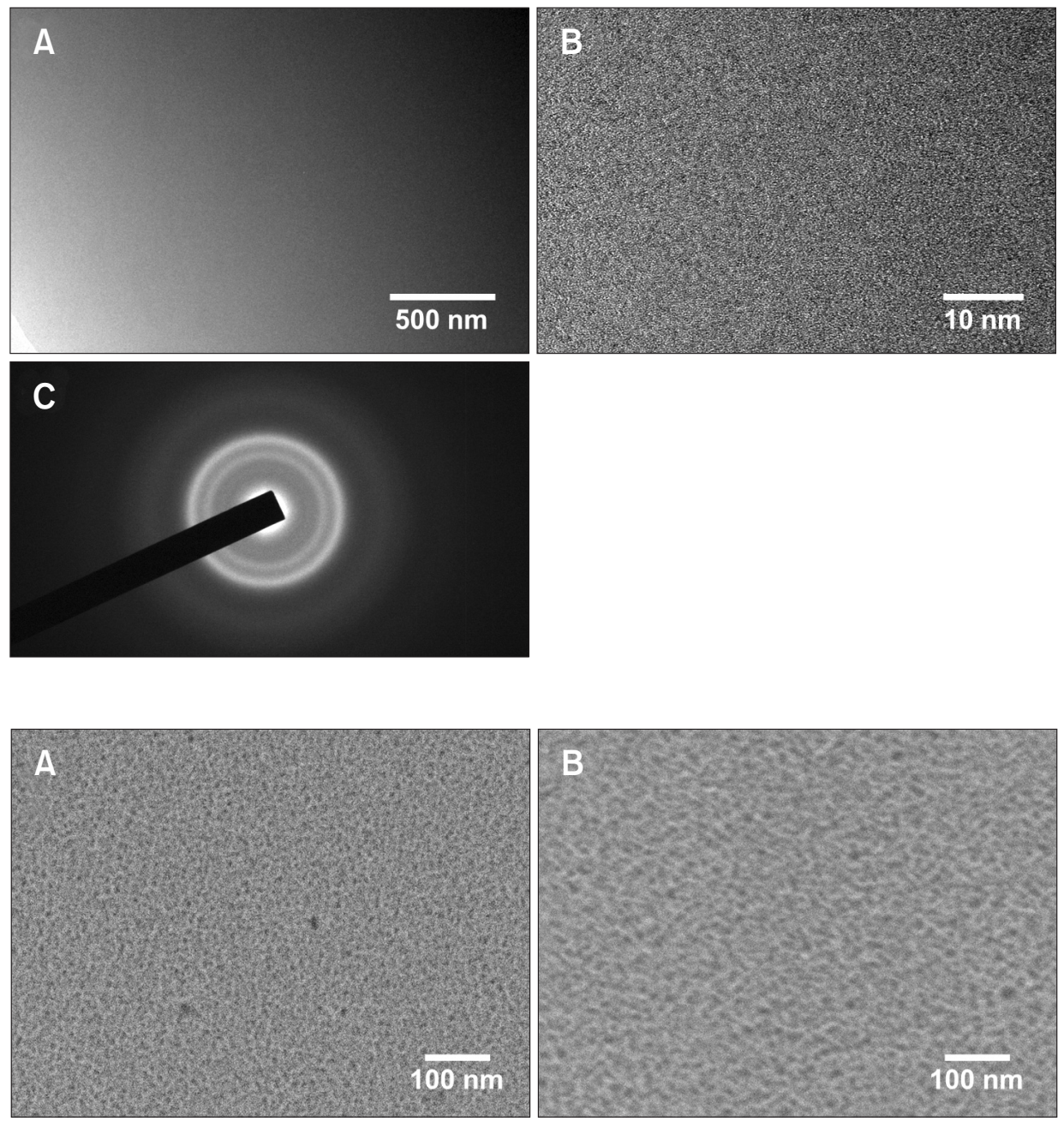

Fig. 2. Secondary electron scanning electron microscope images of dealloyed $\mathrm{Al}_{60} \mathrm{Ge}_{30} \mathrm{Mn}_{10}$ samples at $30^{\circ} \mathrm{C}(\mathrm{A})$ and $60^{\circ} \mathrm{C}$ (B) for 100 hours. 
has been shown that amorphous Ge exhibit some anomalous scattering characteristics (Louzguine et al., 1999), double halo rings observed in the present study may be due to inhomogeneous distribution of $\mathrm{Ge}$ in the amorphous matrix. The previous study has shown that $\sim 3 \mathrm{~nm}$ scale contrast fluctuation is observed in the amorphous matrix due to the local composition variation from $\mathrm{Al}$-rich and $\mathrm{Ge}$-rich regions. TEM results in Fig. 1 indicate that spinodal decomposition in the under-cooled liquid melt above the glass transition temperature during cooling results in $\mathrm{nm}$ scale compositional fluctuation in the as-melt-spun $\mathrm{Al}_{60} \mathrm{Ge}_{30} \mathrm{Mn}_{10}$ ribbon. Since the as-melt-spun alloy exhibit compositional fluctuation due to the presence of Al-rich and Ge-rich regions, dealloying process can be applied to fabricate a nano-porous structure. In the present study, de-alloying of $\mathrm{Al}$ has been tried by immersing the samples in $5 \mathrm{wt} \% \mathrm{HCl}$ aqueous solution at various temperatures for 100 hours.

The secondary electron (SE) SEM images shown in Fig. 2 compare the surface morphology of the samples dealloyed at $30^{\circ} \mathrm{C}$ and $60^{\circ} \mathrm{C}$, respectively. Both samples show a poreligament structure which is a typical surface morphology for dealloyed samples. However, the sample dealloyed at lower temperature exhibit finer pore-ligament structure due to

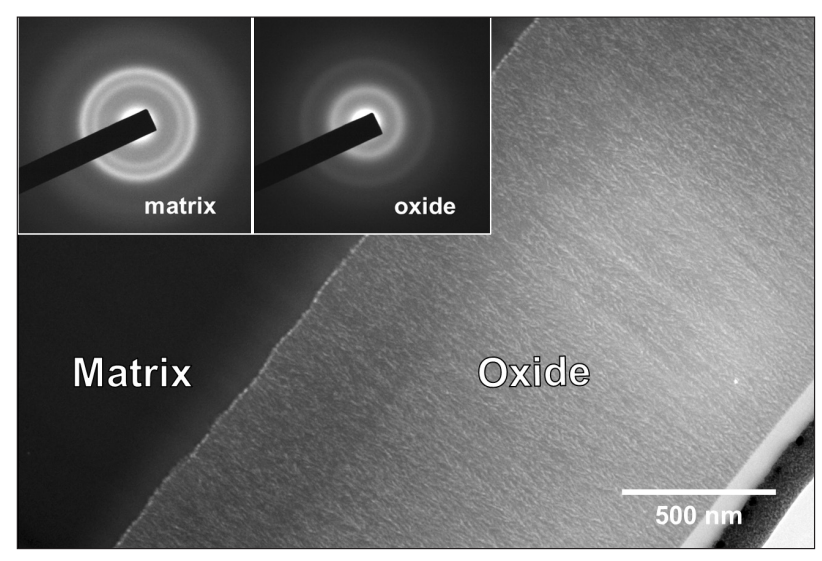

Fig. 3. Cross-sectional bright field transmission electron microscope image (Selected area diffraction pattern of the oxide and matrix is inserted.) obtained from the sample dealloyed at $30^{\circ} \mathrm{C}$ for 100 hours. lower surface diffusion rate as the dealloying temperature decreases.

Fig. 3 shows a typical cross-sectional BF TEM image and SADPs obtained from the sample dealloyed at $30^{\circ} \mathrm{C}$ for 100 hours. The darker-contrast and brighter-contrast regions correspond to undealloyed region (amorphous matrix) and dealloyed region, respectively. The SADP obtained from the undealloyed region indicates that the amorphous matrix after dealloying process exhibits diffuse halo pattern very similar obtained from the as-melt-spun ribbon sample. The SADP obtained from the dealloyed region also exhibits diffuse halo pattern. However, the position of the halo ring is different from those observed from the undealloyed region, indicating that a different amorphous phase forms as a result of dealloying process. The result of detailed analysis in the previous study showed that nano-porous $\mathrm{GeO}_{\mathrm{x}}$ forms as a dealloying product. The interesting point is that nano-porous germanium oxide has an amorphous structure. As already pointed out in the previous study, the critical thickness for amorphous-crystalline transition in germanium oxide may be rather large (Sun, 1947), resulting in the amorphous structure in nano-porous $\mathrm{GeO}_{\mathrm{x}}$.

Fig. 4 shows typical cross-sectional SE SEM images obtained from the samples dealloyed at $40^{\circ} \mathrm{C}$ and $60^{\circ} \mathrm{C}$ for 100 hours. From the SE SEM images, the effect of dealloying temperature on the dealloyed depth from the ribbon surface can be discussed. In the case of the sample dealloyed at $40^{\circ} \mathrm{C}$, the dealloyed depth from the surface was $\sim 4 \mu \mathrm{m}$, indicating that 100 hours is not enough for complete dealloying of the ribbon sample. However, In the case of the sample dealloyed at $60^{\circ} \mathrm{C}$, the ribbon sample was completely dealloyed as can be seen in Fig. 4B. A line with a slightly dark contrast can be observed at the center region, same distance from wheel side and air side. The result in Fig. 4 indicates that the dealloying rate is strongly affected by the dealloying temperature, and is almost same from the wheel and from the air side.

The present study shows that spinodal decomposition of the undercooled liquid in the as-melt-spun $\mathrm{Al}_{60} \mathrm{Ge}_{30} \mathrm{Mn}_{10}$ alloy leads to amorphous phase separation exhibiting double halo diffraction pattern. The de-alloying process has been
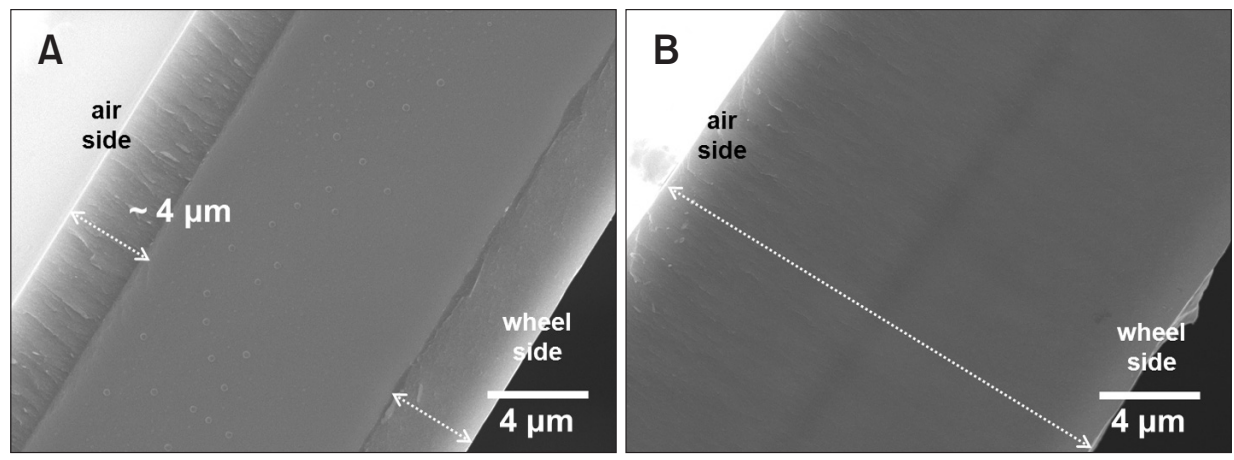

Fig. 4. Cross-sectional secondary electron scanning electron microscope images obtained from the samples dealloyed at $40^{\circ} \mathrm{C}$ (A) and $60^{\circ} \mathrm{C}$ (B) for 100 hours. 
successfully adopted for $\mathrm{Al}_{60} \mathrm{Ge}_{30} \mathrm{Mn}_{10}$ phase separating amorphous alloy by leaching out Al-rich amorphous phase in $5 \mathrm{wt} \% \mathrm{HCl}$ solution. The remaining Ge-rich amorphous phase transforms into an inter-connected porous structure with a typical pore-ligament structure. It is known that the dealloying process consists of three stages, i.e., dissolution, surface diffusion and agglomeration. The present study shows that the dealloying temperature strongly affects the whole dealloying steps including dissolution, surface diffusion and agglomeration. At higher temperature, dissolution kinetics and surface diffusion/agglomeration rate become higher, resulting in the accelerated dealloying kinetics. As a result, coarser pore-ligament structure is obtained as the temperature increases.

\section{CONCLUSIONS}

1. Spinodal decomposition of the undercooled liquid in asmelt-spun $\mathrm{Al}_{60} \mathrm{Ge}_{30} \mathrm{Mn}_{10}$ alloy leads to amorphous phase separation exhibiting double halo diffraction pattern.

2. By immersing the as-melt-spun $\mathrm{Al}_{60} \mathrm{Ge}_{30} \mathrm{Mn}_{10}$ alloy in 5 $\mathrm{wt} \% \mathrm{HCl}$ solution, $\mathrm{Al}$-rich amorphous region is leached out, resulting in an interconnected nano-porous $\mathrm{GeO}_{x}$ with an amorphous structure.

3. The dealloying temperature strongly affects the whole dealloying process. At higher dealloying temperature, dissolution kinetics and surface diffusion/agglomeration rate become higher, resulting in the accelerated dealloying kinetics, i.e., larger dealloying depth and coarser poreligament structure.

\section{CONFLICT OF INTEREST}

No potential conflict of interest relevant to this article was reported.

\section{ACKNOWLEDGMENTS}

This work was supported by the National Research Foundation of Korea (NRF) grant funded by the Korea government (MEST) (No. 2016R1A2B2013838).

\section{REFERENCES}

Chen L, Fujita T, and Chen M (2012) Biofunctionalized nanoporous gold for electrochemical biosensors. Electrochim. Acta 67, 1-5.

Kajita T and Itoh T (2016) Electrochemical sodium storage in amorphous $\mathrm{GeO}_{x}$ powder. Electrochim. Acta 195, 192-198.

Kim K C, Park S H, Na M Y, Chang H J, Kim W T, Mattern N, Eckert J, Yokoyama Y, Kim K B, and Kim D H (2015) Formation of nano-porous $\mathrm{GeO}_{\mathrm{x}}$ by de-alloying of an $\mathrm{Al}-\mathrm{Ge}-\mathrm{Mn}$ amorphous alloy. Scripta Mater. 104, 49-52.

Louzguine D V, Saito M, Waseda Y, and Inoue A (1999) Structural study of amorphous $\mathrm{Ge}_{50} \mathrm{Al}_{40} \mathrm{Cr}_{10}$ alloy. J. Phys. Soc. Jpn. 68, 2298-2303.

Qiu H J, Xu H T, Liu L, and Wang Y (2015) Correlation of the structure and applications of dealloyed nanoporous metals in catalysis and energy conversion/storage. Nanoscale 7, 386-400.
Sun K H (1947) Fundamental condition of glass formation. J. Am. Ceram. Soc. 30, 277-281.

Wang Z, Liu J, Qin C, Yu H, Xia X, Wang C, Zhang Y, Hu Q, and Zhao W (2015) Dealloying of Cu-Based metallic glasses in acidic solutions: products and energy storage applications. Nanomaterials 5, 697721.

Zhang J, Bai Q, and Zhang Z (2016) Dealloying-driven nanoporous palladium with superior electrochemical actuation performance. Nanoscale 8, 7287-7295.

Zhang Z, Wang Y, Qi Z, Zhang W, Qin J, and Frenzel J (2009) Generalized fabrication of nanoporous metals ( $\mathrm{Au}, \mathrm{Pd}, \mathrm{Pt}, \mathrm{Ag}$, and $\mathrm{Cu}$ ) through chemical dealloying. J. Phys. Chem. C 113, 12629-12636. 